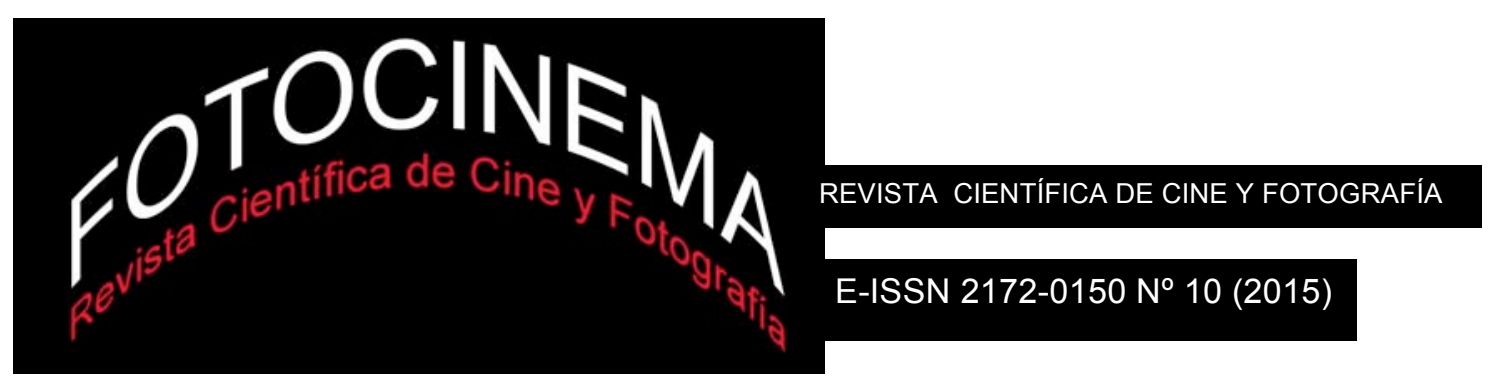

Beatriz de las Heras (ed,) (2014). El fotógrafo como testigo de la Historia. Su retrato en la pantalla. Madrid: Ocho y Medio, 285 pp. Reseña de Máximo Eseverri

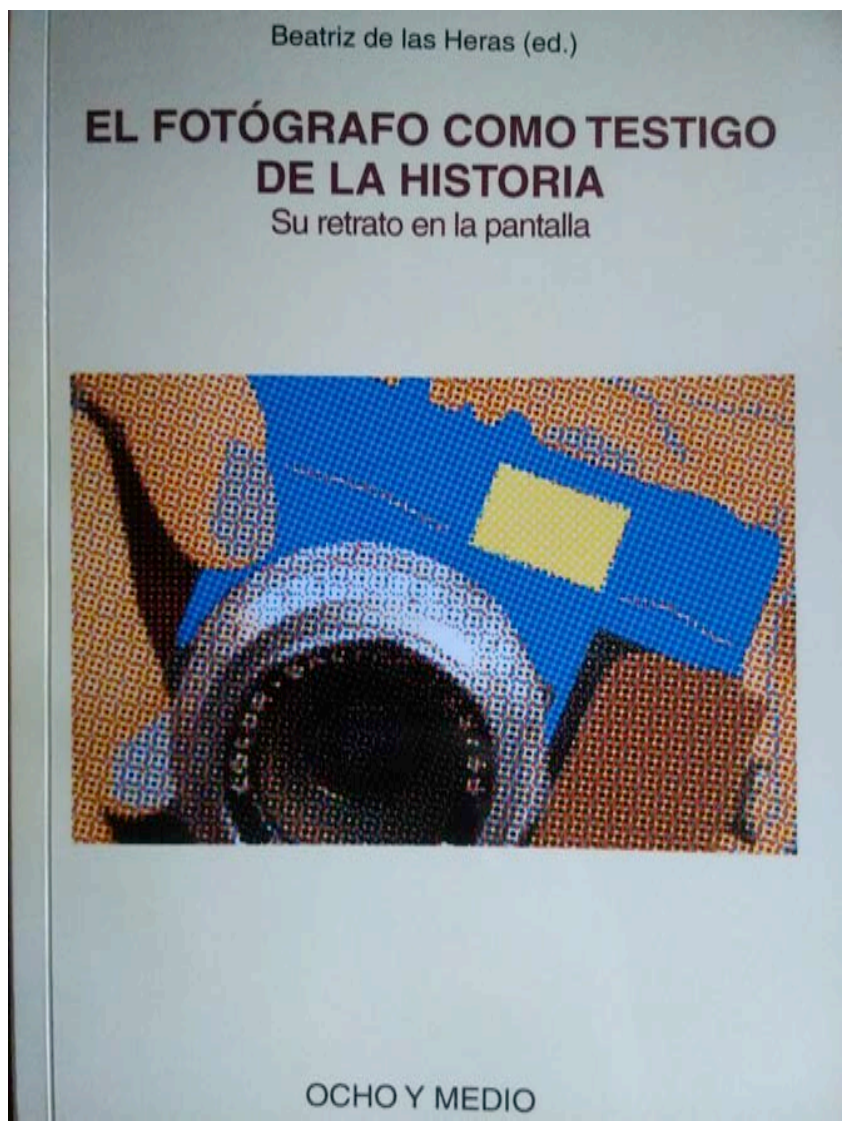

En el convulsionado siglo $\mathrm{XX}$, pletórico de arte y de industria, de maravillas y atrocidades, de pasiones políticas y estéticas; dos prácticas de la imagen visual han colaborado de manera decisiva en la conformación de nuestras concepciones de mundo, nuestra identidad, nuestras memorias individual y social. La fotografía y el cine constituyen formas del ver y del mostrar que por momentos sentimos muy cercanas $\mathrm{y}$ entrelazadas. Y a la vez, cuando nos concentramos en ellas $\mathrm{y}$ auscultamos su naturaleza,

pueden presentársenos como casi opuestas.

El grueso volumen coordinado por la Doctora Beatriz Las Heras -con edición a cargo del Instituto de Cultura y Tecnología, con colaboración de la Facultad de Humanidades, Comunicación y Documentación de la Universidad Carlos III de Madrid- reúne diez artículos en los que, con lucidez y pasión, diferentes especialistas encaran desde diversas perspectivas la relación entre la imagen fotográfica y la cinematográfica. Se trata de un tema inmenso y atrapante, que de inmediato sentimos necesita una reflexión específica como las que ellos han emprendido y que, en el caso de "El fotógrafo como testigo...", tiene lugar en una época de hondas mutaciones en ambos dispositivos. 
La obra se encuentra organizada en dos partes. En la primera, los autores realizan aportes para el establecimiento de un marco general para esta problemática. Allí se ocupan, entre otros temas, de las influencias mutuas entre la fotografía y el cine en sus inicios, cómo ambas formas han aportado a la constitución de imaginarios sociales en diferentes épocas, la conformación de un rango artístico para estas dos prácticas, el lugar social y político del fotógrafo profesional, la relación entre fotografía y cine documental (en este caso, a propósito de la Guerra Civil Española). En la segunda parte se aborda el análisis de diferentes películas que han aludido al fotógrafo en tanto actor social, como Blow Up (1966) de Michelangelo Antonioni, Peeping Tom (1960) del británico Michael Powell o Banderas de nuestros padres (2006), dirigida por Clint Eastwood. Un último texto se ocupa del carácter testimonial de la fotografía a propósito de La caja de música (1989) de Costa-Gavras.

La variedad de obras y temas que se trabajan pareciera señalar la indiscutible vitalidad de un campo en expansión en la academia iberoamericana, así como su integración en un volumen sobre un eje que los abarca habla de las porosidades, entrecruzamientos y múltiples enriquecimientos entre los diferentes textos. Bernardo Riego, de la Universidad de Cantabria, presta atención a lo que llama "fenómenos de borde", que afectan a tecnologías convivientes, en este caso la fotografía y el cine, en distintas épocas en que ellas sufren cambios, se influencian mutuamente, y buscan estabilizarse como dispositivos. Enric Burgos (UPV-UJI) ausculta la triple frontera entre lo artístico, lo científico y lo mediático, que la fotografía y el cine han compartido desde el auge del positivismo. Antonio Pantoja, de la Universidad de Extremadura, ha realizado dos artículos: en el primero repasa trayectorias de fotógrafos que se han convertido en realizadores y directores que han sido inspirados por imágenes fotográficas; en el segundo aborda el caso específico de la dirección de cine en el ámbito español, a lo largo de una centuria y hasta la actualidad. Ignacio Molano, de la Flacso, se ocupa de cómo el fotógrafo profesional y su labor inciden (pueden incidir) en la vida social de sus comunidades, y para ello se sirve de un repaso por diferentes obras emblemáticas del cine moderno que los han retratado. Rafael Rodríguez Tranche (UCM) focaliza en el "primer conflicto bélico que recibió una auténtica cobertura mediática a escala mundial", la 
Guerra Civil Española, y realiza una detallada recuperación y relación de elementos técnicos, políticos y mediáticos de aquella contienda, retratada por ese documental imprescindible que fue (que es) Morir en Madrid. Nekane Parejo, de la Universidad de Málaga, abre la segunda parte del volumen con una reflexión sobre el "acto fotográfico" en dos films del cineasta estadounidense Clint Eastwood, Los puentes de Madison y Banderas de nuestros padres; así como en el primero un fotógrafo y su labor afectan para siempre la vida de una mujer, en el segundo otro fotógrafo, Joe Rosenthal, afecta la vida de millones de compatriotas (y la propia) a través de la gestación de una imagen emblemática, el izado de la bandera estadounidense en Iwo Jima. Pilar Amador Carretero (Universidad Carlos III de Madrid) reflexiona sobre una de las más célebres películas sobre fotógrafos, Blow up, describiendo con agudeza cómo el film dialoga con su época a contrapelo, y cómo encaja en el proyecto creativo de su realizador, quien se basó en un relato del ya centenario Julio Cortázar. "El fotógrafo del pánico. Sobre la imagen, la violencia, el sujeto y la historia" de Víctor Mora (Universidad Carlos III de Madrid) constituye uno de los pasajes más luminosos del libro, en tanto logra rescatar, en el seno de una película subvalorada en su momento, claves esenciales de la ética en la imagen contemporánea, sus riesgos patológicos y su posible carácter sanador. Freud, Gubern y Sontag son algunos de los autores a los que Mora recurre. Cierra el volúmen el artículo de Igor Barrenetxea Marañón (Universidad del País Vasco), sobre La caja de música de Constantin Costa-Gavras. Como señala el autor, en una época (la tardía Guerra Fría), en la que diferentes discursos políticoideológicos buscan imponerse o se alían, unas fotografías halladas pueden constituir un implacable tekmerion capaz de no sólo zanjar un intrincado proceso judicial sino también sellar el destino de la relación de una mujer con su padre. En este film del director de Missing, cine y fotografía se entrelazan para permitir una narración que, como quería Daney, "pensando el mal, no piensa mal".

Atraviesa a casi toda la obra la preocupación por el estatuto y el lugar de la imagen otrora fotoquímica y hoy digital, sea de la fotografía o del cine, en la práctica académica de la Historia, los análisis sociológico y cultural y los estudios de memoria. En diferentes artículos, se busca dar cuenta de una 
genealogía básica de autores que, progresivamente, han incorporado a sus indagaciones y sus "cajas de herramientas" a la foto y al cine, prestando atención y buscando poner en foco la especificidad y el aporte de ambas prácticas. Tal recorrido tiene paradas obligadas en los trabajos de Kracauer y de Benjamin, en las diferentes generaciones de la Escuela de los Annales, en los sociólogos Marc Ferro y Pierre Sorlin, entre otros. Este enfoque, en cuyas coordenadas los autores del libro se ubican, viene a enriquecer y profundizar las reflexiones que habitualmente recurren de manera exclusiva a las teorías centradas en la naturaleza de la imagen propiamente dicha, y reponen para el análisis una dimensión sociohistórica y transdisciplinaria que se revela imprescindible.

\section{Máximo Eseverri}

